\title{
Evaluation of o-cresol removal using PVA-cryogel-immobilised biomass enhanced by PAC
}

\author{
Sylvia See', Poh-Eng Lim*, Jun-Wei Lim², Chye-Eng Seng' and Rohana Adnan' \\ 'School of Chemical Sciences, Universiti Sains Malaysia, Minden, 11800 Penang, Malaysia \\ ${ }^{2}$ Faculty of Agro-Based Industry, Universiti Malaysia Kelantan, Jeli Campus, Locked Bag No. 100, 17600 Jeli, Kelantan, Malaysia
}

\begin{abstract}
The degradation of $o$-cresol using immobilised acclimated biomass in PVA-alginate hydrogel and cryogel beads was investigated. The results show that the PVA-hydrogel-immobilised biomass achieved better $o$-cresol removal efficiency than the PVA-cryogel-immobilised biomass. However, the cryogel beads showed better bead stability and reusability. Based on $o$-cresol removal, the optimum dry biomass density in the cryogel beads of 3-4 mm diameter was found to be $0.02 \mathrm{~g} \cdot \mathrm{cm}^{-3}$. An enhancement in the performance of PVA-cryogel-immobilised biomass for $o$-cresol removal was observed when $0.5 \%$ $(\mathrm{w} / \mathrm{v})$ powdered activated carbon $(\mathrm{PAC})$ was added into the polymeric matrix. In the reusability and stability test, the cryogel beads containing biomass augmented by PAC were able to sustain 9 cycles of use with a removal efficiency of over $82 \%$ per cycle, when treating $300 \mathrm{mg} \cdot \ell^{-1}$ of $o$-cresol, without much biomass leakage being detected.
\end{abstract}

Keywords: cryogel beads, hydrogel beads, $o$-cresol, immobilised biomass, powdered activated carbon

\section{INTRODUCTION}

The biological treatment of phenolic compounds has always made use of suspended biomass systems (Murialdo et al., 2001; Papadimitriou et al., 2009; Durruty et al., 2011; Leong et al., 2011; Lim et al., 2013a; Lim et al., 2013b). However, the common disadvantages associated with the use of this kind of system include a large reactor size requirement to obtain higher biomass amounts, and the occurrence of a biomass settling problem. In order to overcome these problems, the immobilised biomass system has been introduced and is gaining popularity in various wastewater treatment processes (Ratusznei et al., 2000; González et al., 2001; Chen et al., 2002; Kariminiaae et al., 2003; Kuo and Shu, 2004). This system can not only sustain high biomass concentrations but is also able to reduce the bulking effect, as the biomass is entrapped in the polymeric matrices (Petruccioli et al., 2000; Lee et al., 2004; Chen et al., 2005). In addition, the biomass is well insulated from the adverse effect of the presence of hazardous materials and it is also possible to separate and recycle the immobilised biomass after wastewater treatment (Akay et al., 2002).

In general, the common techniques for immobilisation of biomass in a polyvinyl alcohol (PVA) matrix are the boric acid and freeze-thaw methods. The boric acid method has been widely used and is considered to be the simplest and most economical method (Chang and Tseng, 1998). In the conventional approach, a PVA matrix is extruded as droplets through a needle into saturated boric acid solution and spherical PVA beads are formed by cross-linking of the hydroxyl groups of PVA with borate ions (de Queiroz et al., 2006; Idris et al., 2008). Beads formed using this method are considered as hydrogels in which water is the dispersion medium. It has been reported that $800 \mathrm{mg} \cdot \mathrm{e}^{-1} \mathrm{o}$-cresol could be completely removed by acclimated biomass immobilised in PVA hydrogel beads (Toh et al., 2013).

\footnotetext{
To whom all correspondence should be addressed.

喕 +60 4 6533550; fax: +60 4 6574854;

e-mail: pelim@usm.my

Received 6 February 2014; accepted in revised form 26 November 2014.
}

The other immobilisation technique involves PVA cryogels which are prepared by physical cross-linking through the freezing/thawing method (Lozinsky and Plieva, 1998). PVA cryogels have interconnected macropores, thus allowing unhindered diffusion and mass transport of solutes, nano- and even microparticles (Lozinsky et al., 2003). The unique structure of cryogels, in combination with their osmotic, chemical and mechanical stabilities, makes them suitable in the field of wastewater treatment. Furukawa et al. (2009) used the PVA-freezing technique at $-20^{\circ} \mathrm{C}$ to immobilise marine nitrifying sludge, while Vanotti and Hunt (2000) applied the PVA-freezing technique at $-4^{\circ} \mathrm{C}$ to immobilise swine wastewater nitrifying sludge. Magrí et al. (2012) immobilised anammox bacteria in PVA cryogels and obtained $95 \%$ ammonium removal efficiency. They also found that these cryogels were resilient to high nitrite concentrations $\left(244-270 \mathrm{mg} \cdot \ell^{-1} \mathrm{~N}\right)$.

According to previous published findings, both boric acid and freeze-thaw methods have been applied in wastewater treatment and good results were obtained using these methods. However, comparative studies of these two methods for treating phenolic compounds are generally lacking. Therefore, the objectives of this study were: (i) to evaluate the performance of PVA-cryogel-immobilised and PVA-hydrogel-immobilised acclimated biomasses in the removal of $o$-cresol, and (ii) to enhance the reusability and efficiency of PVA-cryogelimmobilised biomass by adding powdered activated carbon (PAC). Activated carbon (AC) is generally an effective adsorbent which could adsorb numerous bio-resistant organic compounds, including $o$-cresol, from the aqueous system (Weber and Morris, 1963; Faust and Aly, 1987; Cecen and Aktas, 2000).

\section{EXPERIMENTAL}

\section{Chemicals}

PVA (average MW of 89000 - 98000 ) with hydrolysed percentage $>99 \%$ from Sigma-Aldrich was used for the synthesis of hydrogel and cryogel beads. The PAC (MALBON S4), 
a steam-activated wood-based carbon purchased from the Century Chemical Works, Malaysia, was dried in the oven at $103-105^{\circ} \mathrm{C}$ for at least $2 \mathrm{~h}$ and kept in the desiccator before use.

\section{Culturing of 0 -cresol acclimated biomass}

Culturing of mixed culture acclimated to $500 \mathrm{mg} \cdot \ell^{-1}$ of $o$-cresol is described in detail for an earlier study (See et al., 2013). This was carried out in a sequencing batch reactor (SBR) with a working volume of $4 \ell$. As the timer used to control the SBR phases required $24 \mathrm{~h}$ to complete 1 sequence, a 24 -h cycle of SBR operation was adopted following the periods of 'fill' $0.5 \mathrm{~h}$; 'react' $8 \mathrm{~h}$; 'settle' $1 \mathrm{~h}$; 'draw' $0.5 \mathrm{~h}$ and 'idle' $14 \mathrm{~h}$. The mixed liquor from the SBR was used to blend with the polymeric matrix forming spherical immobilised biomass beads as described in the following section.

\section{Preparation of immobilised biomass in hydrogel and cryogel beads}

The mixed liquor suspended solids (MLSS) concentration in the SBR was first determined to estimate the amount of biomass per unit volume of mixed liquor. A certain volume of mixed liquor from the SBR was then collected and centrifuged to recover $2 \mathrm{~g}$ of biomass which was then blended with the polymeric matrix with pre-dissolved $7.5 \mathrm{~g}$ PVA and $2 \mathrm{~g}$ alginate to constitute $100 \mathrm{~m} \ell$ of mixture. The biomass-containing polymeric mixture was subsequently extruded into $200 \mathrm{~m} \ell$ gelating solution using a peristaltic pump through a thin borosilicate glass dropper, yielding spherical PVA beads of 3-4 $\mathrm{mm}$ (average of $3.61 \mathrm{~mm}$ ) in diameter, measured using a light microscope image. In the preparation of hydrogel beads, the gelating solution contained saturated boric acid and 1.0\% $(\mathrm{w} / \mathrm{v})$ of $\mathrm{CaCl}_{2}$. The formed hydrogel beads were then gently stirred for $2 \mathrm{~h}$ in the gelating solution for solidification and subsequently washed with tap water under aerated condition, using an aeration pump, until the foaming produced by unpolymerised PVA stopped. In the preparation of cryogel beads, the gelating solution contained $1.0 \%(\mathrm{w} / \mathrm{v})$ of $\mathrm{CaCl}_{2}$ only. The formed beads were transferred into a pan and frozen at $-8 \pm 2^{\circ} \mathrm{C}$ for $18 \mathrm{~h}$. Subsequently, they were slowly thawed at $2 \pm 2^{\circ} \mathrm{C}$ for $6 \mathrm{~h}$. The freezing and thawing process was repeated twice in order to improve the mechanical strength of the cryogel beads (Al-Zuhair and El-Naas, 2011). The cryogel beads were ready to be used after being washed, with tap water under aerated condition using an aeration pump, until the foaming produced by unpolymerised PVA stopped. Thus, the density of dry biomass in the beads was $0.02 \mathrm{~g} \cdot \mathrm{cm}^{-3}$.

\section{Performances of PVA-cryogel-immobilised and PVA- hydrogel-immobilised biomasses}

The performances of immobilised biomass in hydrogel and cryogel beads were compared in terms of bioactivity and reusability by measuring the toxicant removal efficiency and biomass leakage, respectively. The experiment was carried out in two $500-\mathrm{m} \ell$ batch reactors containing $50 \mathrm{~m} \ell$ of the respective immobilised beads and $450 \mathrm{~m} \ell$ of feed solutions with the concentrations of $o$-cresol ranging from 100 to $400 \mathrm{mg} \cdot \ell^{-1}$. The beads in each of the batch reactors were aerated using an aeration pump to maintain the dissolved oxygen (DO) concentration above $4.0 \mathrm{mg} \cdot \ell^{-1}$. Samples were obtained from the reactors at certain intervals for the determination of $o$-cresol concentration until the $o$-cresol concentration was not detected in each batch reactor. For all of the cases, the time course data were fitted to the pseudo-first-order kinetic model with the logarithm form shown in Eq. (1):

$$
\ln C_{t} / C_{\mathrm{o}}=-k_{o-\text { cresol }} t
$$

where:

$C_{\mathrm{o}}$ and $C_{t}$ are the $o$-cresol concentrations initially and at

time $t$, respectively

$k_{o \text {-cresol }}$ is the pseudo-first-order rate constant

The values of $k_{o \text {-cresol }}$ were calculated from the slope of the plot of $\ln C_{t} / C_{\mathrm{o}}$ versus $t$. The experiment was conducted in triplicate for the estimation of standard error.

\section{Determination of optimum dry biomass density in cryogel beads}

Five mixed liquor samples from the SBR containing biomass amounts of $0.5,1.0,1.5,1.8$ and $2.0 \mathrm{~g}$ were collected to prepare the cryogel beads as described above, to obtain beads of 3-4 $\mathrm{mm}$ (average $3.61 \mathrm{~mm}$ ) diameter containing dry biomass density of $0.005,0.01,0.015,0.018$ and $0.02 \mathrm{~g} \cdot \mathrm{cm}^{-3}$, respectively. To each of the beakers filled with $450 \mathrm{~m} \ell$ of feed solution containing $200 \mathrm{mg} \cdot \ell^{-1}$ of $o$-cresol was added $50 \mathrm{~m} \ell$ of each type of cryogel bead. The optimum dry biomass density was chosen based on the amount of biomass in the beads which yielded the fastest rate of $o$-cresol removal characterised by the value of $k_{o}$ cresol calculated using Eq. (1). These experiments were conducted in triplicate for the estimation of standard error.

\section{Performances of suspended biomass and PVA-cryogel- immobilised biomass in o-cresol removal}

The cryogel beads of dry biomass density of $0.02 \mathrm{~g} \cdot \mathrm{cm}^{-3}$ were used in this experiment. Degradation of $o$-cresol (initial concentration ranging from 300 to $500 \mathrm{mg} \cdot \ell^{-1}$ ) by immobilised biomass in $50 \mathrm{~m} \ell$ of cryogel beads and $0.1 \mathrm{~g}$ of suspended biomass in $50 \mathrm{~m} \ell$ of mixed liquor, in two batch reactors containing $450 \mathrm{~m} \ell$ of feed solution, was investigated. The $o$-cresol concentrations were monitored at frequent intervals once aeration was started. The experiment was conducted in triplicate for the estimation of standard error.

\section{Performance of immobilised biomass and PAC in cryogel beads in o-cresol removal}

The preparation of cryogel beads with optimum dry biomass density and $0.5 \%(\mathrm{w} / \mathrm{v})$ PAC was carried out following the same procedure as described above (Preparation of immobilised biomass in hydrogel and cryogel beads). The synthesised cryogel beads were used to study the degradation of $o$-cresol in batch reactors containing feed solutions with concentrations of $o$-cresol ranging from 300 to $500 \mathrm{mg} \cdot \ell^{-1}$. The concentrations of $o$-cresol in the batch reactors were determined at frequent intervals once aeration was started and until $o$-cresol was completely removed in each batch reactor. These experiments were conducted in triplicate for the estimation of standard error.

For comparison with the removal of $o$-cresol solely via biodegradation, the cryogel beads were synthesised without the addition of PAC. The degradation of $o$-cresol at the concentration range of 300 to $500 \mathrm{mg} \cdot \ell^{-1}$ in the batch reactors was then studied. 


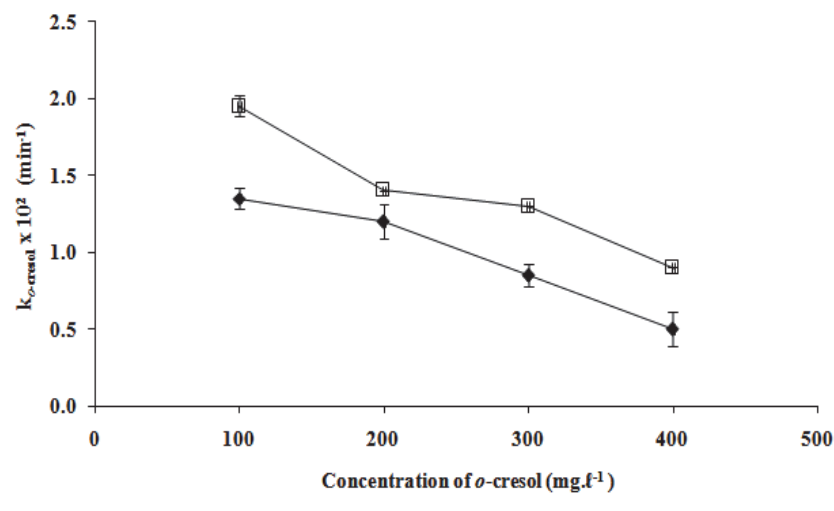

$\bullet$-PVA-cryogel-immobilized biomass $\square$ PVA-hydrogel-immobilized biomass

Figure 1

The pseudo-first-order rate constants of o-cresol removal ( $k_{\text {o-creso }}$ for PVA-cryogel-immobilised and PVA-hydrogel-immobilised biomasses at various initial o-cresol concentrations

\section{Analytical methods}

The $o$-cresol concentration was determined at a $\lambda_{\max }$ of $500 \mathrm{~nm}$ using a UV-Vis spectrophotometer (Thermo Spectronic He $\lambda 10 S \alpha$ ) based on the 4-aminoantipyrine method as described in Standard Methods (APHA, 1998). The MLSS concentration was determined by drying the residue obtained from filtering the mixed liquor to a constant weight at 103 $105^{\circ} \mathrm{C}$ (APHA, 1998). The DO concentration was measured using a DO meter (YSI 550A). The diameter of the spherical PVA bead was determined from the image captured by light microscopy. The analySIS Image Processing (cell^A) program was used to interpret the image and the diameter was calculated after considering the power of magnification. The average diameter of spherical PVA was later determined from at least three readings obtained from the program.

\section{RESULTS AND DISCUSSION}

\section{Comparison of the performances of PVA-cryogel- immobilised and PVA-hydrogel-immobilised biomasses}

Both types of immobilised beads were used in kinetic studies on the removal of $o$-cresol to generate the time course of $o$-cresol concentration. For all of the cases, the time course data gave a good fit to the pseudo-first-order kinetic model. The calculated $k_{o-\text { cresol }}$ using the PVA-cryogel-immobilised and PVA-hydrogelimmobilised biomasses at various initial $o$-cresol concentrations are shown in Fig. 1. It was observed that the rate constants of $o$-cresol removal using the PVA-hydrogel-immobilised biomass were consistently greater than those using the PVA-cryogelimmobilised biomass, for all of the studied concentrations, thus reflecting the relative bioactivity of the biomass encapsulated under the two methods. In the case of cryogel beads, the activity of biomass encapsulated was affected by the process of multiple freeze-thawing, resulting in the lower bioactivity of immobilised biomass as compared with that of the biomass in hydrogel beads.

On the other hand, with respect to reusability, cryogel beads were found to be superior to hydrogel beads in terms of biomass leakage, as shown in Fig. 2. Figure 2a shows that, at the initial concentration of $100 \mathrm{mg} \cdot \ell^{-1} \mathrm{o}$-cresol, the cryogel beads were able to withstand up to 15 cycles $(180 \mathrm{~h})$ of use with aeration, accompanied by only relatively small increases in biomass leakage (from 12 to $15 \mathrm{mg} \cdot \ell^{-1}$ ). This good performance was
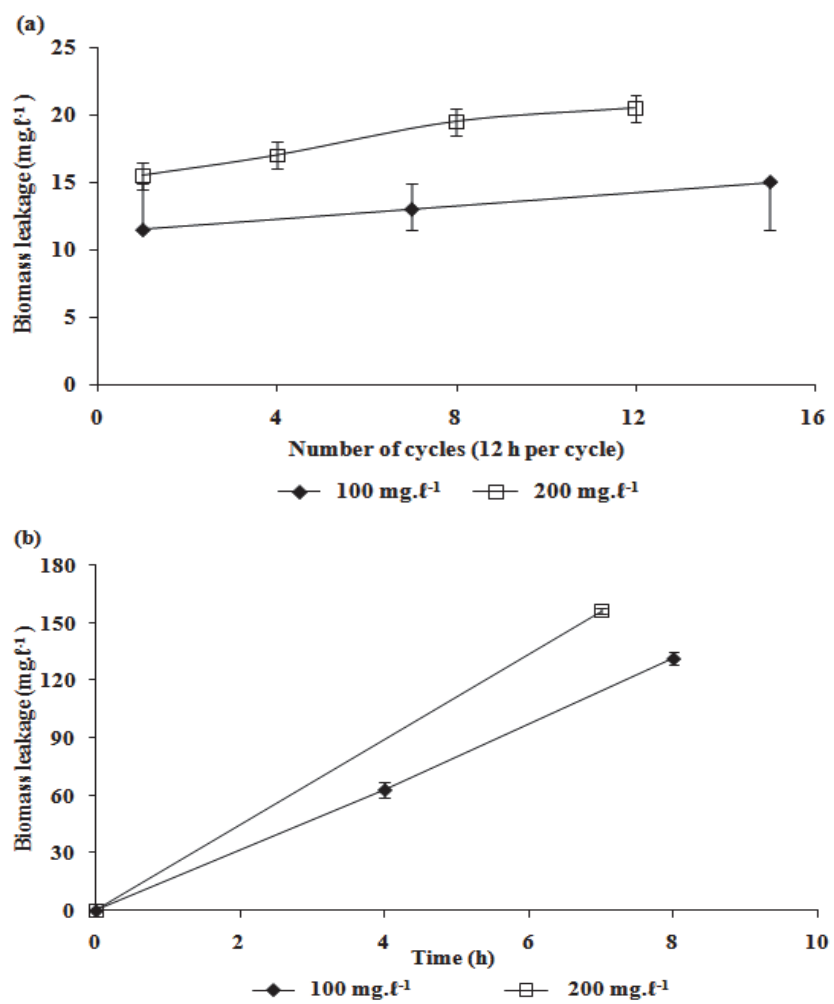

Figure 2

Reusability of (a) cryogel beads and (b) hydrogel beads at initial o-cresol concentrations of 100 and $200 \mathrm{mg} \cdot \mathrm{e}^{-1}$

sustained when the initial $o$-cresol concentration was increased to $200 \mathrm{mg} \cdot \ell^{-1}$ (Fig. 2a). This was due to the fact that the freezing and thawing process forms a system of interconnected pores in the polymeric material, which is a non-brittle gel material and exhibits little abrasive erosion under intense stirring conditions (Zain et al., 2011). In contrast, at the initial $o$-cresol concentration of $100 \mathrm{mg} \cdot \ell^{-1}, 129 \mathrm{mg} \cdot \ell^{-1}$ of biomass was detected after only $8 \mathrm{~h}$ of aeration for hydrogel beads and the biomass leakage was even higher when the initial $o$-cresol concentration was increased to $200 \mathrm{mg} \cdot \ell^{-1}$. The greater amount of biomass leakage could be explained by the labile polar covalent interactions formed between the borate ions and the alcohol groups of PVA by cross-linking. These interactions are constantly and rapidly breaking and reforming, resulting in the unusual intermediate solid and liquid properties which cause the beads to be easily dissolved in water (Zain et al., 2011).

\section{Determination of optimum dry biomass density in cryogel beads}

The optimum dry biomass density for the preparation of the cryogel beads was determined based on the amount of biomass in the beads which completely removed $o$-cresol within the shortest period. The results of the batch $o$-cresol degradation experiments using cryogel beads with different dry biomass densities showed that the synthesised cryogel beads with dry biomass density of $0.02 \mathrm{~g} \cdot \mathrm{cm}^{-3}$ required the shortest time ( $480 \mathrm{~min}$ ) for the complete removal of $200 \mathrm{mg} \cdot \ell^{-1} \mathrm{o}$-cresol, as compared with the others. Figure 3 shows the calculated rate constant values based on the pseudo-first-order kinetic model for cryogel beads of dry biomass density varying from 0.005 to $0.02 \mathrm{~g} \cdot \mathrm{cm}^{-3}$. It was observed that the fastest rate of toxicant removal was achieved 


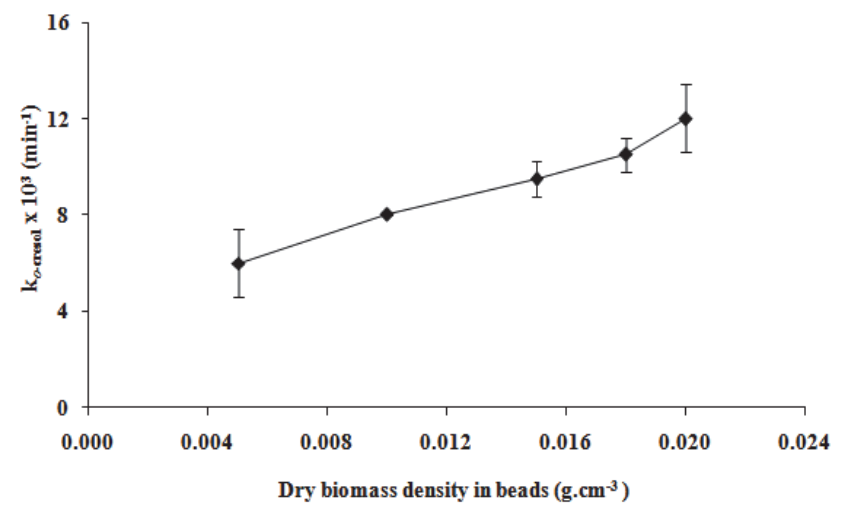

Figure 3

The pseudo-first-order rate constants ( $k_{\text {o-creso }}$ ) of o-cresol removal at different dry biomass density in cryogel beads
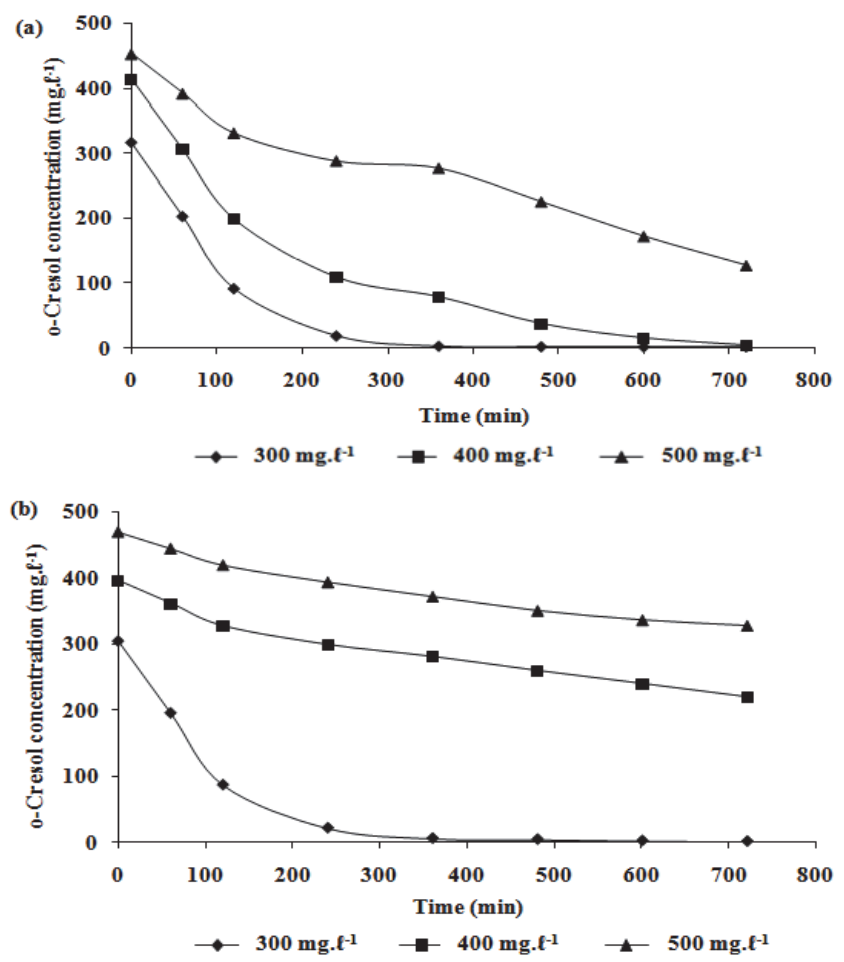

Figure 4

Time courses of o-cresol removal at different initial o-cresol concentrations in $500 \mathrm{~m} \ell$ of solution using (a) $50 \mathrm{ml}$ of cryogel beads of $0.02 \mathrm{~g} \cdot \mathrm{cm}^{-3}$ dry biomass density and (b) $0.1 \mathrm{~g}$ of suspended biomass

when the dry biomass density was $0.02 \mathrm{~g} \cdot \mathrm{cm}^{-3}$. However, when the dry biomass density exceeded $0.02 \mathrm{~g} \cdot \mathrm{cm}^{-3}$, it was found that beads of larger size ( $4-5 \mathrm{~mm}$ diameter) were formed. As beads with larger diameter would encounter more diffusion restrictions due to lower surface area/volume ratios (Nunes et al., 2010), $0.02 \mathrm{~g} \cdot \mathrm{cm}^{-3}$ was selected as the optimum dry biomass density for the preparation of cryogel beads.

\section{Comparison between the performances of suspended and PVA-cryogel-immobilised biomasses for o-cresol removal}

The time courses of $o$-cresol concentration at different initial $o$-cresol concentrations, in the presence of $50 \mathrm{~m} \ell$ of cryogel

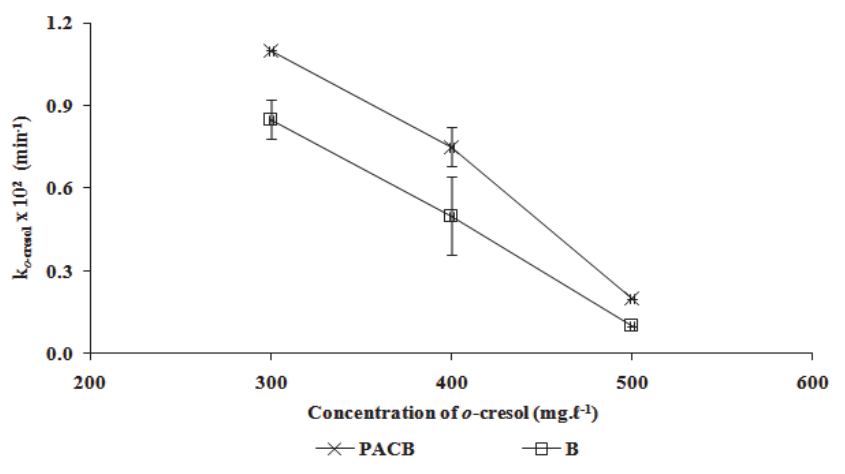

Figure 5

The pseudo-first-order rate constants of o-cresol removal ( $\left.k_{\text {o-cresol }}\right)$ using immobilised PAC and biomass (PACB) and immobilised biomass alone $(B)$ in cryogel beads

beads of $0.02 \mathrm{~g} \cdot \mathrm{cm}^{-3}$ dry biomass density and $0.1 \mathrm{~g}$ of suspended biomass, are shown in Figs $4 \mathrm{a}$ and b, respectively. It was observed that both the immobilised and suspended biomasses achieved almost the same removal efficiency at the initial $o$-cresol concentration of $300 \mathrm{mg} \cdot \ell^{-1}$. However, the ability of suspended biomass to remove $o$-cresol decreased drastically as compared with the immobilised biomass when the initial $o$-cresol concentration was increased to $400 \mathrm{mg} \cdot \mathrm{l}^{-1}$. At this concentration, the immobilised biomass was still able to achieve $100 \%$ removal of $o$-cresol after a reaction time of about $720 \mathrm{~min}$, whereas the suspended biomass could only remove up to $45 \%$ of the toxicant within the same period. This observation indicates that the immobilised biomass was better protected from the inhibitory effect exerted by higher concentration of $o$-cresol than the suspended biomass, due to the dilution of $o$-cresol while penetrating the polymer gel without direct contact with the biomass (Zhou and Fang, 1997).

\section{Enhancement of o-cresol removal and reusability using immobilised biomass supplemented by PAC in cryogel beads}

The removal of $o$-cresol was investigated using both types of cryogel beads (containing dry biomass density of $0.02 \mathrm{~g} \cdot \mathrm{cm}^{-3}$ ), one with immobilised biomass only and the other with immobilised biomass supplemented by PAC for the initial concentrations of $o$-cresol from 300 to $500 \mathrm{mg} \cdot \ell^{-1}$. The time course data for $o$-cresol removal were fitted to the pseudo-first-order kinetic model; the pseudo-first-order rate constants for $o$-cresol removal $\left(k_{\text {o-cresol }}\right)$, obtained from both batch reactors at different initial $o$-cresol concentrations, are shown in Fig. 5. It was observed that although the rate constant values of $o$-cresol removal in both systems decreased rapidly with the increase in initial $o$-cresol concentration from 300 to $500 \mathrm{mg} \cdot \ell^{-1}$, faster removal of $o$-cresol was achieved by the system using immobilised biomass supplemented by PAC for all of the different initial concentrations of $o$-cresol studied. This could be explained by the initial adsorption of $o$-cresol by PAC, which lowered the $o$-cresol concentration, thus reducing the inhibitory effect exerted by the toxicant.

The reusabilities of cryogel beads with immobilised biomass only, and with immobilised biomass supplemented by $\mathrm{PAC}$, in terms of percentage $o$-cresol removal with number of cycles of use, for initial $o$-cresol concentrations of 300 and $400 \mathrm{mg} \cdot \ell^{-1}$, are shown in Fig. 6. It was observed that, at initial $o$-cresol concentration of $300 \mathrm{mg} \cdot \ell^{-1}$, the cryogel beads with immobilised biomass supplemented by PAC were able 


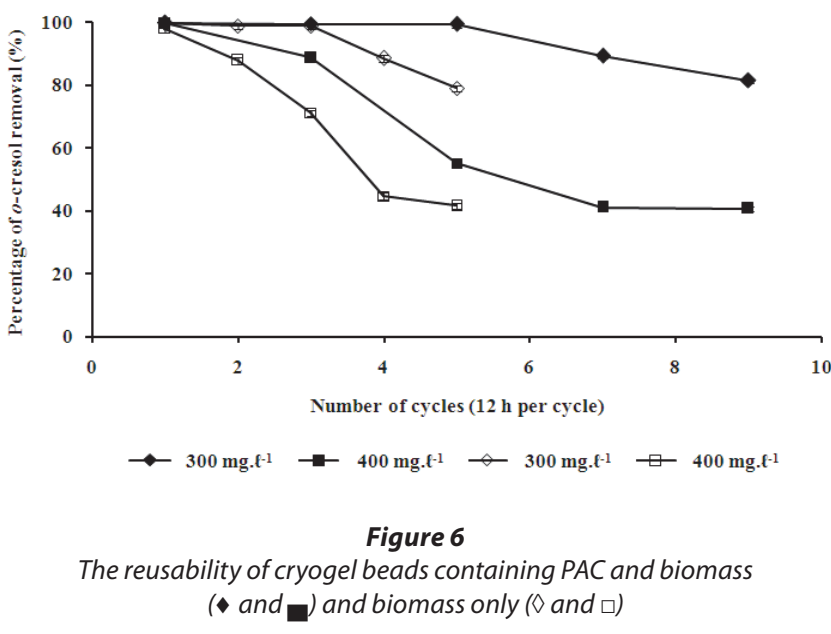

to achieve almost $100 \% o$-cresol removal for up to 5 cycles of use, and still maintained $82 \%$ removal efficiency after 9 cycles of use. In addition, negligible biomass leakage was observed after the experiment (data not shown). In contrast, the $o$-cresol removal efficiency deteriorated rapidly after only 3 cycles of use when cryogel beads with biomass only were used. This indicates that the presence of PAC had strengthened the stability of the beads resulting in minimal biomass leakage. However, at an initial $o$-cresol concentration of $400 \mathrm{mg} \cdot \ell^{-1}$, the $o$-cresol removal efficiency decreased rapidly after only one cycle of use for both systems, though the rate of decrease was much faster for the system using cryogel beads with biomass only. The progressive decrease in $o$-cresol removal efficiency with increasing number of cycles of use could be explained by the increase in bead size due to the growth of biomass during the recycling process. The increase in initial $o$-cresol concentration would lead to more biomass growth, resulting in earlier bead size increase and eventual disintegration of the beads. These results thus clearly illustrate the role of PAC in maintaining the integrity of the beads.

\section{CONCLUSIONS}

The PVA-hydrogel-immobilised biomass showed better $o$-cresol removal efficiency as compared to the PVA-cryogelimmobilised biomass, but the cryogel beads were preferred in terms of bead stability and reusability. The optimum dry biomass density in the beads was found to be $0.02 \mathrm{~g} \cdot \mathrm{cm}^{-3}$. The immobilised biomass in cryogel beads yielded higher $o$-cresol removal efficiency than the suspended biomass at higher initial $o$-cresol concentration, due to the mitigation effect by the PVAalginate matrix. The immobilised biomass augmented by PAC in cryogel beads was found to improve the $o$-cresol removal efficiency as well as the stability and reusability of the beads.

\section{ACKNOWLEDGEMENTS}

Financial support from the Universiti Sains Malaysia under the Research University (RU) Grant No. 1001/PKIMIA/814149 is gratefully acknowledged. Sylvia See wishes to acknowledge the financial support from MyBrain 15 MyMaster.

\section{REFERENCES}

AKAY G, ERHAN E, KESKINLER B and ALGUR OF (2002) Removal of phenol from wastewater using membrane-immobilized enzymes - Part II. Cross-flow filtration. J. Membr. Sci. 206 61-68.
AL-ZUHAIR S and EL-NAAS M (2011) Immobilization of Pseudomonas putida in PVA gel particles for the biodegradation of phenol at high concentrations. Biochem. Eng. J. 56 46-50.

APHA (1998) Standard Methods for the Examination of Water and Wastewater $\left(20^{\text {th }}\right.$ edn.). American Public Health Association, Washington, DC.

CECEN F and AKTAS O (2000) Effect of PAC addition in combined treatment of landfill leachate and domestic wastewater in semicontinuously fed batch and continuous-flow reactors. Water $S A$ 27 177-188.

CHANG CC and TSENG SK (1998) Immobilization of Alcaligenes eutrophus using PVA crosslinked with sodium nitrate. Biotechnol. Technol. 12 865-868.

CHEN BY, CHEN SY and CHANG JS (2005) Immobilized cell fixedbed bioreactor for wastewater decolorization. Process Biochem. 40 3434-3440.

CHEN KC, CHEN CY, PENG JW and HOUNG JY (2002) Real-time control of an immobilized-cell reactor for wastewater treatment using ORP. Water Res. 36 230-238.

DE QUEIROZ AAA, PASSOS ED, ALVES SD, SILVA GS, HIGA OZ and VITOLO M (2006) Alginatepoly(vinyl alcohol) core-shell microspheres for lipase immobilization. J. Appl. Polym. Sci. 102 1553-1560.

DURRUTY I, OKADA E, GONZALEZ JF and MURIALDO SE (2011) Degradation of chlorophenol mixtures in a fed-batch system by two soil bacteria. Water SA 37 547-552.

FAUST SD and ALY OM (1987) Adsorption Process for Water Treatment. Butterworths Publication, Guildford.

FURUKAWA K, INATOMI Y, QIAO S, QUAN L, YAMAMOTO T, ISAKA K and SUMINO T (2009) Innovative treatment system for digester liquor using anammox process. Bioresour. Technol. 100 5437-5443.

GONZÁLEZ G, HERRERA G, GARCARCÍA MT and PEÑA M (2001) Biodegradation of phenolic industrial wastewater in a fluidized bed reactor with immobilized cells of Pseudomonas putida. Bioresour. Technol. 80 137-142.

IDRIS A, ZAIN NAM and SUHAIMI MS (2008) Immobilization of Baker's yeast invertase in PVA-alginate matrix using innovative immobilization technique. Process Biochem. 43 331-338.

KARIMINIAAE HR, KANDA K and KATO F (2003) Wastewater treatment with bacteria immobilized onto a ceramic carrier in an aerated system. J. Biosci. Bioeng. 95 128-132.

KUO WC and SHU TY (2004) Biological pre-treatment of wastewater containing sulfate using anaerobic immobilized cells. J. Hazardous Mater. 113 147-155.

LEE WK, CHUNG J, BAE W, PARK SJ, KIM Y, LEE YW and PARK DW (2004) Operational factor for nitrite accumulation from a mixed culture by cell-immobilization. J. Ind. Eng. Chem. 10 959-966.

LEONG ML, LEE KM, LAI SO and OOI BS (2011) Sludge characteristics and performances of the sequencing batch reactor at different influent phenol concentrations. Desalination 270 181-187.

LIM JW, LIM PE, SENG CE and ADNAN R (2013a) Evaluation of aeration strategy in moving bed sequencing batch reactor performing simultaneous 4-chlorophenol and nitrogen removal. Appl. Biochem. Biotechnol. 170 831-840.

LIM JW, SENG CE, LIM PE, NG SL, TAN KC and KEW SL (2013b) Response of low-strength phenol-acclimated activated sludge to shock loading of high phenol concentrations. Water SA 39 695-700.

LOZINSKY VI, GALAEV IY, PLIEVA FM, SAVINA IN, JUNGVID $\mathrm{H}$ and MATTIASSON B (2003) Polymetric cryogels as promising materials of biotechnological interest. Trends Biotechnol. 10 445-451.

LOZINSKY VI and PLIEVA FM (1998) Poly (vinyl alcohol) cryogels employed as matrices for cell immobilization. 3. Overview of recent research and developments. Enzym. Microb. Tech. 23 227-242.

MAGAGRÍ A, VANOTTI MB and SZÖGI AA (2012) Anammox sludge immobilized in polyvinyl alcohol (PVA) cryogel carriers. Bioresour. Technol. 114 231-240.

MURIALDO SE, FENOGLIO R, HAURE PM and GONZALEZ JF (2001) Degradation of phenol and chlorophenols by mixed and pure cultures. Water SA 29 457-463. 
NUNES MAP, VILA-REAL H, FERNANDES PCB and RIBEIRO MHL (2010) Immobilization of Naringinase in PVA-alginate matrix using an innovative technique. Appl. Biochem. Biotechnol. 160 2129-2147.

PAPADIMITRIOU CA, SAMARAS P and SAKELLAROPOULOS GP (2009) Comparative study of phenol and cyanide containing wastewater in CSTR and SBR activated sludge reactors. Bioresour. Technol. 100 31-37.

PETRUCCIOLI M, DUARTE J and FEDERICI F (2000) High-rate aerobic treatment of winery wastewater using bioreactors with free and immobilized activated sludge. J. Biosci. Bioeng. 90 381-386.

RATUSZNEI SM, RODRIGUES JAD, CAMARGO EFM, ZAIAT M and BORZANI W (2000) Feasibility of a stirred anaerobic sequencing batch reactor containing immobilized biomass for wastewater treatment. Bioresour. Technol. 75 127-132.

SEE S, LIM JW, LIM PE, SENG CE, NG SL and ADNAN R (2013) Enhancement of $o$-cresol removal using PAC and acclimated biomass immobilized in polyvinyl alcohol hydrogel beads. Desalin. Water Treatment DOI: 10.1080/19443994.2013.833874.

TOH RH, SENG CE, LIM PE, ADNAN R and AHMAD SUJARI

AN (2013) Biodegradation of $o$-cresol by polyvinyl alcoholalginate immobilized mixed culture. Desalin. Water Treatment $\mathbf{5 1}$ 7216-7222.

VANOTTI MB and HUNT PG (2000) Nitrification treatment of swine wastewater with acclimated activated sludge immobilized in polymer pellets. Trans. ASAE 43 405-413.

WEBER Jr. WJ and MORRIS JC (1963) Kinetics of adsorption on carbon from solution. J. Sanit. Eng. Div.18 31-42.

ZAIN NAM, SUHAIMI MS and IDRIS A (2011) Development and modification of PVA-alginate as a suitable immobilization matrix. Process Biochem. 46 2122-2129.

ZHOU GM and FANG HHP (1997) Anoxic treatment of low-strength wastewater by immobilized sludge. Water Sci. Technol. 36 135-141. 